\title{
MODEL PERTUMBUHAN DUA SAMPEL
}

\author{
Sudarno \\ Program Studi Statistika FMIPA UNDIP
}

\begin{abstract}
Growth curve model is generalization of the multivariate regression models. This paper determine growth curve model at two samples of ras. They are observed body weight after given by substances. The problems will be done are testing for an outlier, testing for multivariate normality, testing for hogeneous, test of the adequacy of the model, and estimate of the parameters model. In doing computation and visualization of statistics at needed formulas, use up date some softwares, such as SAS, Minitab, MATLAB, etc. If the estimated model is known, it can be used to some objectives. The estimate model could be applied to predicted tool for next time, give characteristic and properties of the model. The growth of rat which be given thyroxin substance, at beginning time cause significant increasing of the body weight, but after at sixth weeks, given substance imply significant decreasing of their body weight, too. Meanwhile for the rat be given thyouracil, at beginning time to tenth weeks, their body weight affect slowly increasing by continue. Therefore thyroxin substance should be given before seventh weeks, but for thyouracil substance could be given continuosly if cause increasing the body weight. This result could be used to optimalization of rat growth.
\end{abstract}

Key words: Multivariate normal test, Adequacy of model test, Growth curve model.

\section{Pendahuluan}

Sesuatu yang mengalami pertumbuhan, perkembangannya dipengaruhi oleh waktu. Sehingga dapat dibuat hubungan antara pertumbuhannya dengan waktu. Untuk membuat hubungan ini, dapat menggunakan hubungan linier antara keduanya, yaitu memakai model regresi linier univariat atau berganda. Perluasan dari model regresi ini dan untuk variabel responnya jamak, menggunakan model regresi multivariate, yang biasa disebut model kurva pertumbuhan ${ }^{[8]}$. Model kurva pertumbuhan dua sampel merupakan perluasan dari model kurva pertumbuhan satu sampel. Agar memenuhi asumsi seperti yang dipersyaratkan dalam teori, perlu uji normal multivatiat, yaitu untuk mengetahui bahwa sebaran data berdistribusi normal multivariate dengan vector rataan $\mu$ dan matriks variankovarian $\Sigma^{[7]}$. Untuk uji kecocokan model menggunakan uji rasio likelihood ${ }^{[9]}$. Sedangkan menurut Khatri (1966), untuk mendapatkan taksiran model yang cocok perlu penaksir likelihood maksimum koefisien regresi $\hat{\Psi}$ dan matriks varian-kovarian $\Sigma$.

Tulisan ini akan menentukan model kurva pertumbuhan pada dua sampel, yaitu mencari model pertumbuhan berat tikus yang diberi zat thyroxin dan berat tikus yang diberi zat thiouracil dengan lima kali waktu pengamatan. Pembahasannya pertama kali mendeteksi pencilan, menguji distribusi normal multivariate, memeriksa kehomogenan, pengusulan model, pencocokan model, dan menentukan taksiran model, serta kegunaan taksiran model.

Sistem komputasi dan visualisasi statistik yang muncul pada rumus yang ada, menggunakan beberapa perangkat lunak: SAS,Minitab, SPSS dan MATLAB. Dengan mendapatkan taksiran model kurva pertumbuhan, maka akan dapat dipergunakan sebagai alat prediksi untuk waktu yang lain. Selain itu taksiran model juga berguna untuk mengetahui sifat-sifat pertumbuhan tikus dengan diberi zat tertentu. 


\section{Uji Asumsi dan Model Kurva Pertumbuhan Dua Sampel 2.1. Uji Normal Multivariat dan Uji Kehomogenan Deteksi Pencilan}

Langkah awal pembahasan dilakukan dengan pendeteksian pencilan. Tujuannya untuk mengetahui keseragaman populasi. Pencilan adalah hasil pengamatan yang memiliki karakteristik unik yang terlihat sangat berbeda jauh dari pengamatan lainnya dan muncul dalam bentuk nilai ekstrim baik untuk variabel tunggal atau variable multivariat. Pencilan dapat dianalisis dengan dua cara, yaitu analisis terhadap pencilan univariat dan analisis terhadap pencilan multivariat.

\section{Pencilan pada Data Univariat}

Deteksi terhadap adanya pencilan data univariat dapat dilakukan dengan menentukan nilai ambang batas yang akan dikategorikan sebagai pencilan dengan cara mengkonversi nilai data penelitian kedalam z-score, yang mempunyai rataan nol dan simpangan baku satu. Bila nilai-nilai telah dinyatakan dalam z-score, maka perbandingan antar besaran nilai dengan mudah dapat dilakukan. Nilai pengamatan yang mempunyai z-score lebih dari 3 atau z-score kurang dari -3 akan dikategotikan sebagai pencilan.

\section{Pencilan pada Data Multivariat}

Untuk mendeteksi adanya pencilan pada data multivariate, yaitu dengan mengukur jarak dari tiap nilai pengamatan ke pusat data (rataan semua variabel) dengan menggunakan jarak Mahalanobis ${ }^{[2]}$.

Diasumsikan sejumlah $n$ vektor pengamatan independen $\mathbf{x}_{1}, \mathbf{x}_{2}, \ldots, \mathbf{x}_{\mathbf{n}}$ berdistribusi $\mathrm{N}_{\mathrm{p}}(\mu, \Sigma)$. Diberikan $\mathbf{x}_{\mathbf{j}}$ adalah vektor pengamatan, maka jarak Mahalanobis antara $\mathbf{x}_{\mathbf{j}}$ dan $\overline{\mathbf{x}}$ didefinisikan sebagai berikut:

$$
d_{j}^{2}=\left(\mathbf{x}_{\mathbf{j}}-\overline{\mathbf{x}}\right) \mathbf{S}^{-1}\left(\mathbf{x}_{\mathbf{j}}-\overline{\mathbf{x}}\right), \quad j=1,2, \ldots, n
$$

dengan $\overline{\mathbf{x}}$ adalah vektor rataan sampel dan $\mathbf{S}$ merupakan matriks kovarian sampel. Jarak Mahalanobis tersebut dievaluasi dengan distribusi $\chi_{\alpha, p}^{2}$ untuk $p$ adalah banyaknya variabel respon yang diamati. Hasil pengamatan yang mempunyai nilai $d_{j}^{2}>\chi_{\alpha, p}^{2}$ merupakan pencilan pada data multivariat.

\section{Uji Normal Multivariat}

Selanjutnya dilakukan pemeriksaan asumsi. Asumsi-asumsi yang diperlukan dalam pembentukan model kurva pertumbuhan adalah sebagai berikut:

1. Error $\varepsilon_{\mathbf{j k}}$ diasumsikan berdistribusi normal multivariat dengan vektor rataan merupakan vektor nol dan matriks varian-kovarian $\Sigma$.

2. Matriks varian-kovarian sama untuk semua perlakuan.

\section{Pemeriksaan Asumsi:}

\section{Pemeriksaan asumsi normal multivariat}

Pemeriksaan asumsi normal multivariat dilakuakn pada vektor error $\varepsilon_{j k}$, yaitu dengan mengetahui hubungan linier antara $d_{j}^{2}$ dan $q_{j}$ yang dilakukan menggunakan uji koefisien korelasi $r$. Hipotesisnya adalah:

$\mathrm{H}_{0}: r=0$ (Tidak terdapat hubungan linier antara $d_{j}^{2}$ dan $q_{j}$ )

$\mathrm{H}_{1}: r \neq 0$ (Terdapat hubungan linier antara $d_{j}^{2}$ dan $q_{j}$ ) 
Statistik hitung: $t=r \sqrt{\frac{n-2}{1-r^{2}}}$, dengan derajat bebas $n-2, \mathrm{n}=$ banyaknya pengamatan.

Pengambilan keputusan:

Jika $|t|>t_{\alpha / 2}$, maka tolak $\mathrm{H}_{0}$, atau menggunakan tolak $\mathrm{H}_{0}$, jika $P$-value $<\alpha$. Artinya terdapat hubungan linier antara $d_{j}^{2}$ dan $q_{j}$.

\section{Uji Kehomogenan}

Pemeriksaan asumsi kehomogenan beberapa matriks varian-kovarian dilakukan dengan Uji Box'M menggunakan hipotesis berikut:

$$
\begin{aligned}
& \mathrm{H}_{0}: \Sigma_{\mathbf{1}}=\Sigma_{\mathbf{2}}=\cdots=\Sigma_{\mathbf{J}}=\Sigma_{\mathbf{0}} \\
& \mathrm{H}_{1}: \text { Terdapat dua diantara } \Sigma_{\mathbf{j}} \neq 0
\end{aligned}
$$

Karena $\Sigma_{\mathbf{j}}$ tidak diketahui, maka diduga menggunakan matriks varian-kovarian dari data pengamatan, yaitu dengan $\mathbf{S}$.

Diketahui statistik uji Box'M:

$$
\mathbf{M}=\sum_{\mathrm{j}=1}^{\mathrm{J}}\left(\mathrm{n}_{\mathrm{j}}-1\right) \ln |\mathbf{S}|-\sum_{j=1}^{J}\left(n_{j}-1\right) \ln \left|\mathbf{S}_{\mathbf{j}}\right|
$$

dengan

$$
\mathbf{S}_{\mathbf{j}}=\frac{1}{n-1} \sum_{j=1}^{j}\left(y_{j .}-\bar{y}_{j}\right)\left(y_{j .}-\bar{y}_{j}\right) \text { dan } \mathbf{S}=\frac{\sum_{j=1}^{J}\left(n_{j}-1\right) \mathbf{S}_{\mathbf{j}}}{\sum_{j=1}^{J}\left(n_{j}-1\right)} .
$$

Maka M dipergunakan untuk mencari nilai $\mathrm{MC}^{-1}$ dengan

$$
\mathrm{C}^{-1}=1-\frac{\left(2 p^{2}+3 p-1\right)}{6(p+1)(J-1)}\left(\sum_{j=1}^{J} \frac{1}{\left(n_{j}-1\right)}-\frac{1}{\sum_{j=1}^{J}\left(n_{j}-1\right)}\right) .
$$

Keputusan: Tolak $\mathrm{H}_{0}$, jika $\mathrm{MC}^{-1}>\chi^{2}$ tabel dengan derajat bebas: $\frac{1}{2}(J-1) p(p+1)$.

\subsection{Model Kurva Pertumbuhan Dua Sampel}

Pada model kurva pertumbuhan dua sampel diamati respon dari sekumpulan obyek untuk dua kelompok populasi yang dikenai perlakuan yang berbeda, setelah beberapa periode waktu. Model kurva pertumbuhan yang terbentuk dapat diketahui setelah beberapa periode waktu terdapat efek atau respon perlakuan.

Misal dilakukan percobaan yang melibatkan subyek-subyek yang berasal dari dua kelompok populasi berbeda yang dikenai dua perlakuan berbeda dalam $p$ periode waktu. Diberikan $u_{t}$ dan $v_{t}$ yang mewakili respon dari subyek-subyek selama waktu $t=0,1, \ldots, p-1$ dengan $p$ merupakan periode pengamatan yang diamati dari dua kelompok populasi yang berbeda. Diasumsikan model kurva pertumbuhan berbentuk polinomial berderajat $m-1$ dengan $m \leq p$. Maka taksiran modelnya

$$
\begin{aligned}
& E\left(u_{t}\right)=\xi_{0}+\xi_{1} t+\xi_{2} t^{2}+\cdots+\xi_{m-1} t^{m-1} \\
& E\left(v_{t}\right)=\gamma_{0}+\gamma_{1} t+\gamma_{2} t^{2}+\cdots+\gamma_{m-1} t^{m-1}
\end{aligned}
$$


Dari dua populasi yang diamati diperoleh $\mathrm{n}_{1}$ pengamatan dari populasi 1 dan $\mathrm{n}_{2}$ pengamatan dari populasi 2, maka:

$$
\mathbf{U}^{\prime}=\left[\begin{array}{ccc}
u_{10} & \cdots & u_{n_{1} 0} \\
\vdots & \cdots & \vdots \\
u_{1 p-1} & \cdots & u_{n_{1} p-1}
\end{array}\right] \text { dan } \mathbf{V}^{\prime}=\left[\begin{array}{ccc}
u_{10} & \cdots & u_{n_{2} 0} \\
\vdots & \cdots & \vdots \\
u_{1 p-1} & \cdots & u_{n_{2} p-1}
\end{array}\right]
$$

adalah transpose matrik pengamatan. Sehingga

$$
\begin{aligned}
& E\left(\mathbf{U}^{\prime}\right)=(\mu, \ldots, \mu)=\mu \mathbf{1}_{\mathbf{n}_{1}}^{\prime}=\mathbf{B}^{\prime} \Psi_{1} \mathbf{1}_{\mathbf{n}_{1}}^{\prime} \\
& E\left(\mathbf{V}^{\prime}\right)=(\mu, \ldots, \mu)=\mu \mathbf{1}_{\mathbf{n}_{1}}^{\prime}=\mathbf{B}^{\prime} \Psi_{2} \mathbf{1}_{\mathbf{n}_{2}}^{\prime}
\end{aligned}
$$

dengan $\mathbf{B}^{\prime}$ adalah matrik berukuran $p$ x $m$ sedangkan $\boldsymbol{\Psi}_{1}$ dan $\boldsymbol{\Psi}_{2}$ merupakan matrik parameter yang berukuran $m \times 1$, yaitu

$$
\mathbf{B}^{\prime}=\left[\begin{array}{cccc}
1 & t_{0} & \cdots & t_{0}^{m-1} \\
1 & t_{1} & \cdots & t_{1}^{m-1} \\
\vdots & \vdots & \vdots & \vdots \\
1 & t_{p-1} & \cdots & t_{p-1}^{m-1}
\end{array}\right], \quad \Psi_{1}=\left[\begin{array}{c}
\xi_{0} \\
\vdots \\
\xi_{m-1}
\end{array}\right], \quad \Psi_{2}=\left[\begin{array}{c}
\gamma_{0} \\
\vdots \\
\gamma_{m-1}
\end{array}\right] \text { dan } \mathbf{1}_{\mathrm{r}} \text { adalah vektor-r dari }
$$

satu.

Dengan mengambil

$$
\mathbf{Y}=\left[\begin{array}{l}
\mathbf{U} \\
\mathbf{V}
\end{array}\right], \Psi=\left[\begin{array}{l}
\Psi_{1}^{\prime} \\
\Psi_{2}^{\prime}
\end{array}\right] \text {, dan } \mathbf{A}=\left[\begin{array}{cc}
\mathbf{1}_{\mathbf{n}_{1}} & \mathbf{0} \\
\mathbf{0} & \mathbf{1}_{\mathbf{n}_{2}}
\end{array}\right]
$$

dapat ditulis modelnya:

$$
E(\mathbf{Y})=\mathbf{A} \Psi \mathbf{B}
$$

Secara umum, model kurva pertumbuhan dinyatakan sebagai berikut ${ }^{[6]}$

$$
\mathbf{Y}=\mathbf{A} \Psi \mathbf{B}+\mathbf{E}
$$

dengan $\mathbf{Y}$ merupakan matrik pengamatan berukuran $n \times p$, dan "baris" matriks $\mathbf{E}$ adalah iid $N_{p}(\mathbf{0}, \Sigma)$. Matrik A dan B merupakan matrik diketahui masing-masing berukuran $n \times q$ dan $m \times p$, dan matrik $\boldsymbol{\Psi}$ adalah matrik parameter belum diketahui berukuran $q \times \mathrm{x}$. Diasumsikan bahwa A : $n \times q$ berrank $q \leq n$ dan B : $m \times p$ berrank $m \leq p$, dengan $p$ adalah periode pengamatan dan $q$ adalah jumlah sampel atau kelompok yang akan dibentuk kurva pertumbuhannya.

\section{Uji Kecocokan Model}

Uji kecocokan model dipergunakan untuk mengetahui model kurva pertumbuhan yang terbentuk cocok atau tidak untuk diterapkan pada data. Maka sebelum melakukan uji kecocokan model diasumsikan dulu model polinomial derajat berapa yang kira-kira cocok untuk diterapkan pada data. Setelah diasumsikan model polinomial yang cocok untuk diterapkan pada data, maka selanjutnya akan diuji kecocokan modelnya dengan menggunakan hipotesis berikut ini:

$\mathrm{H}_{0}: \mu=\mathbf{B}^{\prime} \Psi$ (Model cocok) vs $\mathrm{H}_{1}: \mu \neq \mathbf{B}^{\prime} \Psi$ (Model tidak cocok)

Dalam model regresi linier multivariate diperoleh model $\mathbf{Y}=\mathbf{A} \Xi+\mathbf{E}$, dengan $\mathbf{Y}: n \times p, \mathbf{A}$ $: n \times q, \boldsymbol{\Xi}: q \times p$, dan $n$ baris dari matriks $\mathbf{E}: n \times p$ adalah iid $\mathrm{N}_{\mathrm{p}}(\mathbf{0}, \Sigma), \Sigma>0$. Supaya model ini merupakan model kurva pertumbuhan maka $\boldsymbol{\Xi}$ harus berbentuk $\Xi=\Psi \mathbf{B}$, dengan matrik $\boldsymbol{\Psi}$ berukuran $q \times m$ dan matrik $\mathbf{B}$ berukuran $m \times p$ yang berrank $m \leq p$. Makanya, terdapat matrik $\mathbf{C}:(p-m) \times p$ berrank $p-m$ sedemikian hingga $\mathbf{B C}^{\prime}=\mathbf{0}$. Dengan demikian agar memenuhi model kurva pertumbuhan, maka $\Xi \mathbf{C}^{\prime}=\mathbf{0}$. 
Jika diambil

$$
\begin{aligned}
\mathbf{W} & =\mathbf{Y}^{\prime}\left[\mathbf{I}-\mathbf{A}\left(\mathbf{A}^{\prime} \mathbf{A}\right)^{-\mathbf{1}} \mathbf{A}^{\prime}\right] \mathbf{Y} \\
\mathbf{V}_{\mathbf{1}} & =\mathbf{Y}^{\prime} \mathbf{A}\left(\mathbf{A}^{\prime} \mathbf{A}\right)^{-\mathbf{1}} \mathbf{A}^{\prime} \mathbf{Y}
\end{aligned}
$$

dan

$$
\lambda_{1}=\frac{|\mathbf{C W C}|}{\left|\mathbf{C}\left(\mathbf{W}+\mathbf{V}_{1}\right) \mathbf{C}^{\prime}\right|}
$$

Statistik hitung untuk uji kecocokan model kurva pertumbuhan adalah ${ }^{[9]}$ :

$$
\chi^{2}=-\left[f-\frac{1}{2}(p-m-q+1)\right] \log \left(\lambda_{1}\right)
$$

dengan $f=n-q$.

Uji rasio likelihood didapat keputusan tolak $\mathrm{H}_{0}$ jika $\chi^{2} \geq \chi_{q(p-m), \alpha}^{2}$.

Artinya model kurva pertumbuhan yang terbentuk tidak cocok untuk diterapkan pada data.

\section{Taksiran Parameter}

Setelah model yang diasumsikan cocok untuk diterapkan. Selanjutnya akan dicari penaksir likelihood maksimum dari parameter $\Psi$, menggunakan rumus ${ }^{[4]}$

$$
\hat{\Psi}=\left(\mathbf{A}^{\prime} \mathbf{A}\right)^{-1} \mathbf{A}^{\prime} \mathbf{Y} \mathbf{W}^{-1} \mathbf{B}^{\prime}\left(\mathbf{B W}^{-1} \mathbf{B}^{\prime}\right)^{-1}
$$

dengan $\mathbf{W}$ seperti persamaan (4).

\section{Pembahasan}

Suatu penelitian bertujuan untuk menyelidiki pengaruh pemberian zat thyroxin dan thiouracil pada air minum tikus terhadap pertumbuhan berat tikus, yang diukur pada 7 ekor tikus yang diberi zat thyroxin dan 10 ekor tikus yang diberi zat thiouracil. Respon yang diamati adalah berat tikus sebelum air minumnya dicampur zat thyroxin dan thiouracil dan pada 1, 2, 3, dan 4 minggu setelah pemberian zat tersebut. Diperoleh data hasil pengamatan sebagai berikut ${ }^{[1]}$.

Tabel 1. Data Berat Tikus (gram)

\begin{tabular}{|l|c|c|c|c|c|c|}
\hline \multirow{2}{*}{ Kelompok } & Individu & \multicolumn{5}{|c|}{ Waktu (minggu) } \\
\cline { 2 - 6 } & & $\mathbf{0}$ & $\mathbf{1}$ & $\mathbf{2}$ & $\mathbf{3}$ & $\mathbf{4}$ \\
\hline \multirow{5}{*}{ Thiroxin } & 1 & 59 & 85 & 121 & 156 & 191 \\
& 2 & 54 & 71 & 90 & 110 & 138 \\
& 3 & 56 & 75 & 108 & 151 & 189 \\
& 4 & 59 & 85 & 116 & 148 & 177 \\
& 5 & 57 & 72 & 97 & 120 & 144 \\
& 6 & 52 & 73 & 97 & 116 & 140 \\
& 7 & 52 & 70 & 105 & 138 & 171 \\
\hline \multirow{5}{*}{ Thiourcil } & 8 & 61 & 86 & 109 & 120 & 129 \\
& 9 & 59 & 80 & 101 & 111 & 122 \\
& 10 & 53 & 79 & 100 & 106 & 133 \\
& 11 & 59 & 88 & 100 & 111 & 122 \\
& 12 & 51 & 75 & 101 & 123 & 140 \\
& 13 & 51 & 75 & 92 & 100 & 119 \\
& 14 & 56 & 78 & 95 & 103 & 108 \\
& 15 & 58 & 69 & 93 & 114 & 138 \\
& 16 & 46 & 61 & 78 & 90 & 107 \\
& 17 & 53 & 72 & 89 & 104 & 109 \\
\hline
\end{tabular}


Berdasarkan data tersebut diketahui pengukuran berat tikus diambil sebanyak 5 kali, sehingga pada percobaan tersebut, banyaknya variabel respon adalah $p=5$. Langkah-langkah yang dilakukan pada pengujian ini adalah berikut ini:

\section{Pendeteksian pencilan}

Langkah awal dilakukan pengujian terhadap pencilan univariat dilakukan standarisasi data dalam bentuk z-score dengan rataan nol dan simpangan baku satu. Didapat hasil bahwa tidak terdapat nilai z-score di luar interval -3 sampai 3. Maka dapat disimpulkan bahwa tidak terdapat pencilan untuk data univariat.

Selanjutnya dilakukan uji terhadap pencilan multivariat dengan menggunakan criteria jarak Mahalanobis $\left(d^{2}{ }_{j}\right)$ yang dievaluasi menggunakan distribusi $\chi_{0,05 ; 5}^{2}$. Diperoleh hasil jarak Mahalanobis terkecil dan terbesar, masing-masing adalah 0,793 dan 9,266. Selain itu $\chi_{0,05 ; 5}^{2}=11,07$. Karena $d_{j}^{2}<\chi_{0,05 ; 5}^{2}$, maka dapat disimpulkan bahwa tidak terdapat pencilan untuk data multivariat.

\section{Pengujian asumsi normal multivariat}

Untuk memeriksa asumsi normal multivariate, pertama dilakukan perhitungan error $\varepsilon_{j k}$ dan matriks varian-kovarian $\mathbf{S}$. Diperoleh hasil matriks varian-kovarian:

$$
\mathbf{S}=\left[\begin{array}{ccccc}
15,7384 & 21,6545 & 25,1232 & 28,3768 & 28,1791 \\
21,6545 & 50,8098 & 56,0911 & 56,3464 & 57,3597 \\
25,1232 & 56,0911 & 86,7786 & 112,1589 & 122,1731 \\
28,3768 & 56,3464 & 112,1589 & 183,5286 & 208,0358 \\
28,1791 & 57,3597 & 122,1731 & 208,0358 & 292,8514
\end{array}\right]
$$

Berdasarkan uji korelasi $r$ dengan hipotesis:

$$
\begin{aligned}
& \left.\mathrm{H}_{0}: r=0 \text { (Tidak terdapat hubungan linier antara } d_{j}^{2} \text { dan } q_{j}\right) \\
& \left.\mathrm{H}_{1}: r \neq 0 \text { (Terdapat hubungan linier antara } d_{j}^{2} \text { dan } q_{j}\right)
\end{aligned}
$$

Didapat hasil nilai koefisien korelasi 0,831 dengan $P$-value $=0,00$, maka untuk $\alpha=0,05$ dapat disimpulkan bahwa $\mathrm{H}_{1}$ diterima dengan kata lain terdapat hubungan linier antara $d_{j}^{2}$ dan $q_{j}$. Oleh karena itu error dapat dikatakan berdistribusi normal multivariat.

\section{Pemeriksaan asumsi kehomogenan}

Pemeriksaan asumsi kehomogenan menggunakan matrik varian-kovarian. Asumsi ini dilakukan dengan bantuan Uji Box'M menggunakan hipotesis:

$$
\begin{aligned}
& \mathrm{H}_{0}: \Sigma_{1}=\Sigma_{2} \\
& \mathrm{H}_{1} \text { : Terdapat } \Sigma_{\mathbf{j}}, \mathrm{j}=1,2 \text { yang tidak sama }
\end{aligned}
$$

Berdasarkan komputasi didapat hasil $\mathbf{M}=19,790$. Selanjutnya ditentukan nilai $\mathbf{M C}^{-1}$ yang akan dibandingkan dengan nilai distribusi $\chi^{2}$. Berdasarkan Persamaan (1) didapat nilai

$$
\mathbf{C}^{-1}=1-\frac{2(5)^{2}+3(5)-1}{6(5+1)(2-1)}\left[\left(\frac{1}{6}+\frac{1}{9}\right)-\frac{1}{6+9}\right]=0,625,
$$

maka $\mathbf{M C}^{\mathbf{1}}=12,369$.

Dengan mengambil $\alpha=0,05$ didapat harga $\chi_{15 ; 0,05}^{2}=24,99$. Karena 12,369 lebih kecil dari pada 24,99 maka $\mathrm{H}_{0}$ diterima, artinya matrik varian-kovarian adalah homogen. 
Karena terpenuhinya asumsi-asumsi di atas, maka analisis terhadap data dapat dilanjutkan dengan pembentukan model kurva pertumbuhan melalui Uji Kecocokan Model. Uji ini dipergunakan untuk mengetahui model kurva pertumbuhan yang terbentuk cocok atau tidak untuk diterapkan. Untuk data tikus diambil periode pengamatan $p=5, m$ $=4, q=2$. Sehingga matriks $\mathbf{B}$ berukuran $4 \times 5$, dan matriks $\Psi$ berukuran $2 \times 4$, yang berarti model kurva pertumbuhan terbaiknya menggunakan model polinomial derajat tiga.

Misal model kurva pertumbuhan yang cocok diasumsikan berbentuk model polinomial pangkat tiga, maka menurut Persamaan (2) dan (3), bahwa model kurva pertumbuhan untuk kelompok tikus yang air minumnya diberi zat thyroxin dan zat thiouracil, masing-masing adalah ${ }^{[6]}$

$$
E\left(y_{1}\right)=\xi_{0}+\xi_{1} t+\xi_{2} t^{2}+\xi_{3} t^{3}
$$

dan

$$
E\left(y_{2}\right)=\gamma_{0}+\gamma_{1} t+\gamma_{2} t^{2}+\gamma_{3} t^{3}
$$

Selanjutnya dilakukan uji kecocokan model dengan menggunakan hipotesis:

$\mathrm{H}_{0}: \mu=\mathbf{B}^{\prime} \Psi$ (Model cocok) vs $\mathrm{H}_{1}: \mu \neq \mathbf{B}^{\prime} \Psi$ (Model tidak cocok)

Dalam hal ini, matriks B berukuran 4 x 5 yang berrank 4 , yaitu

$$
\mathbf{B}=\left[\begin{array}{ccccc}
1 & 1 & 1 & 1 & 1 \\
0 & 1 & 2 & 3 & 4 \\
0 & 1 & 4 & 9 & 16 \\
0 & 1 & 16 & 27 & 64
\end{array}\right],
$$

matriks $\mathbf{Y}$ berukuran 17 x 5 dengan elemen data penelitian seperti pada Tabel 1, matriks $\mathbf{A}$ berukuran 17 x 2 dengan bentuk $\mathbf{A}=\left[\begin{array}{ll}\mathbf{1}_{7} & \mathbf{0}_{7} \\ \mathbf{0}_{10} & \mathbf{1}_{10}\end{array}\right]$, dengan matriks $\mathbf{1}_{7}$ berukuran 7 x 1 yang berelemen 1 , matriks $\mathbf{0}_{7}$ berukuran 7 x 1 yang berelemen 0 , matriks $\mathbf{0}_{\mathbf{1 0}}$ berukuran 10 x 1 yang berelemen 0 , dan matriks $\mathbf{1}_{\mathbf{1 0}}$ berukuran $10 \mathrm{x} 1$ yang berelemen 1 . Sedangkan matriks $\mathbf{C}$ berukuran 1 x 5 mempunyai rank 1 sedemikian hingga $\mathbf{B C}=\mathbf{0}$, yaitu $\mathbf{C}=\left[\begin{array}{lllll}-5 & 12 & -6 & -4 & 3\end{array}\right]$. Sehingga berdasarkan Persamaan (4) dan (5), matriks $\mathbf{W}$ dan $\mathbf{V}_{\mathbf{1}}$ dapat ditentukan. Akibatnya berdasarkan Persamaan (6), diperoleh nilai $\lambda_{1}=0,696$. Selain itu berdasarkan Persamaan (7) dapat ditentukan nilai statistik hitung, yaitu $\chi^{2}=5,432$, dan statistik tabel $\chi_{2 ; 0,05}^{2}=5,991$. Karena nilai statistik hitung lebih kecil dari nilai statistik tabel maka $\mathrm{H}_{0}$ diterima, yang artinya model kurva pertumbuhan cocok untuk dipergunakan.

Selanjutnya dicari taksiran likelihood maksimum dari parameter $\Psi$, berdasarkan Persamaan (8) didapat hasil:

$$
\hat{\Psi}=\left[\begin{array}{rrrr}
55,990 & 15,248 & 6,309 & -0,833 \\
55,360 & 24,342 & -2,119 & 0,069
\end{array}\right]
$$

Baris pertama pada matriks tersebut merupakan penaksir parameter dari kelompok tikus yang diberi zat thyroxin, sedangkan baris kedua merupakan penaksir parameter dari kelompok tikus yang diberi zat thiouracil. Karena telah diperoleh nilai penaksir dari kedua kelompok tikus, maka dapat dibentuk taksiran model kurva pertumbuhannya. Berdasarkan Persamaan (9), (10), dan (11), masing-masing didapat taksiran model:

Taksiran model kurva pertumbuhan untuk kelompok tikus yang diberi zat thyroxin adalah:

$$
\hat{y}_{1}=55,99+15,248 t+6,309 t^{2}-0,833 t^{3} \text {. }
$$


Taksiran model kurva pertumbuhan untuk kelompok tikus yang diberi zat thiouracil adalah:

$$
\hat{y}_{2}=55,36+24,342 t-2,119 t^{2}+0,069 t^{3} .
$$

Jika dilakukan prediksi dari waktu mula-mula sampai sepuluh minggu didapat hasil seperti yang disajikan pada tabel berikut ini:

Tabel 2. Hasil prediksi model dua sampel.

\begin{tabular}{|c|c|c|c|}
\hline Nomor & $t$ (minggu) & $\hat{y}_{1}$ (gram) & $\hat{y}_{2}$ (gram) \\
\hline 1 & 0 & 55,990 & 55,360 \\
2 & 1 & 76,714 & 77,652 \\
3 & 2 & 105,058 & 96,120 \\
4 & 3 & 136,024 & 111,178 \\
5 & 4 & 164,614 & 123,240 \\
6 & 5 & 185,830 & 132,720 \\
7 & 6 & 194,674 & 140,032 \\
8 & 7 & 186,148 & 145,590 \\
9 & 8 & 155,254 & 149,808 \\
10 & 9 & 96,994 & 153,100 \\
11 & 10 & 6,370 & 155,880 \\
\hline
\end{tabular}

Sedangkan apabila dilakukan visualisasikan dalam bentuk grafik diperoleh gambar seperti di bawah ini:

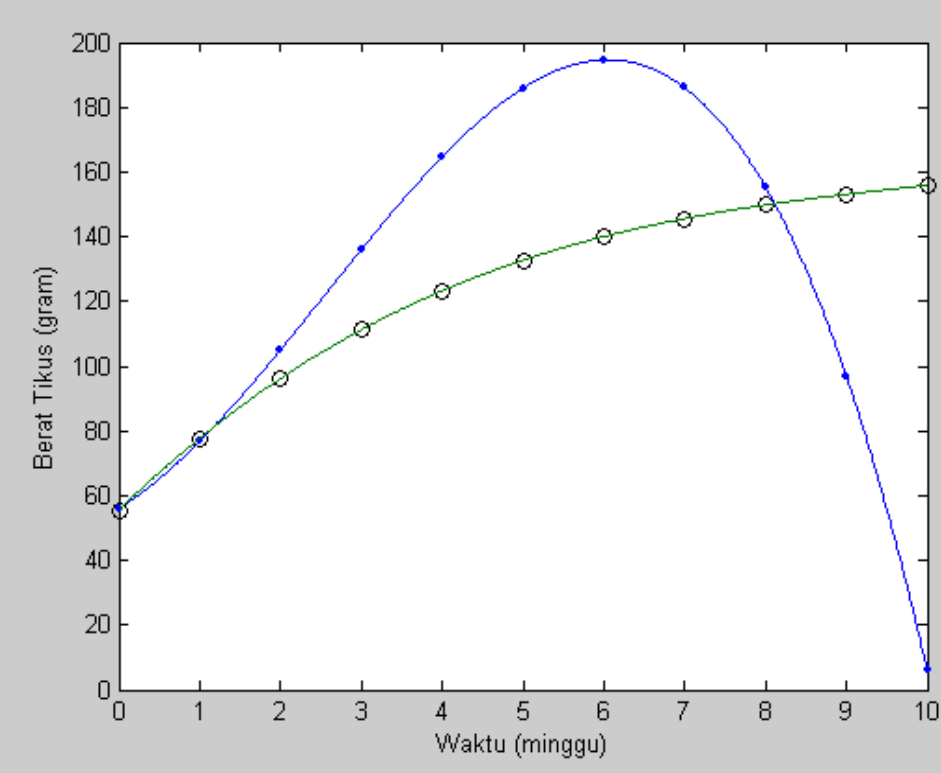

Gambar 1. Grafik pertumbuhan dua sampel tikus.

Berdasarkan Tabel 2 dan Gambar 1, terlihat bahwa pertumbuhan tikus yang diberi zat thyroxin awalnya mengalami kenaikan berat badan yang cepat, tetapi setelah minggu keenam mengalami penurunan berat badan yang drastis pula. Sedangkan untuk tikus yang diberi zat thiouracil dari awal sampai minggu kesepuluh tetap mengalami kenaikan berat badan terus, walaupun lambat. Hal ini berarti pemberian zat thyroxin cukup diberikan sampai minggu keenam, sedangkan pemberian zat thiouracil dapat diberikan terus selama masih berpengaruh pada kenaikan berat badan tikus. 


\section{Kesimpulan}

Berdasarkan pembahasan di atas didapat hasil bahwa taksiran model pertumbuhan tikus dengan diberi zat thyroxin dan zat thiouracil, masing-masing adalah

$$
\hat{y}_{1}=55,99+15,248 t+6,309 t^{2}-0,833 t^{3} \quad \text { dan }
$$

$\hat{y}_{2}=55,36+24,342 t-2,119 t^{2}+0,069 t^{3}$.

Pertumbuhan tikus yang diberi zat thyroxin awalnya mengalami kenaikan berat badan yang signifikan, tetapi setelah pemberian pada minggu keenam mengalami penurunan berat badan yang signifikan pula. Sedangkan untuk tikus yang diberi zat thiouracil dari awal sampai minggu kesepuluh tetap mengalami kenaikan berat badan, walaupun lambat. Maka pemberian zat thyroxin cukup diberikan sampai minggu keenam, sedangkan untuk pemberian zat thiouracil dapat diberikan terus selama masih terjadi kenaikan berat tikus.

\section{DAFTAR PUSTAKA}

1. Christensen, R., Linear Models for Multivariate, Time Series and Spatial Data, Springer-Verlag, Inc., New York, 1991.

2. Jobson, J.D., Applied Multivariate Data Analysis: Categorical and Multivariate Method, Vol. $2^{\text {nd }}$, Springer-Verlag, Inc., New York, 1992.

3. Johnson, R.A. and Wichern, D.W., Applied Multivariate Statistical Analysis, Prentice_Hall, Inc., New Jersey, 1982.

4. Khatri, $\bar{C}$.G., A note on a MANOVA model applied to problems in growth curve, Ann. Stat. Math., 1966, 18: 75-86.

5. Moore, H., MATLAB for Engineers, Prentice Hall, New Jersey, 2007.

6. Potthof, R.F. and Roy, S.N., A Generalized Multivariate Analisys of Variance Model useful especially for Growth Curve Problems, Biometrika, 1964, 51: 313 - 326.

7. Srivastava, M.S., A Measures of Skewness and Kurtosis and a Graphical Method for Assessing Multivariate Normality, Statistics and Probability, 1984, 2: 263 - 267.

8. Srivastava, M.S., Methods of Multivariate Statistics, John Wiley \& Sons, Inc., New York, 2002.

9. Srivastava, M.S. and Carter, E.M., An Introduction to Applied Multivariate Statistics, North-Holland, New York, 1983. 